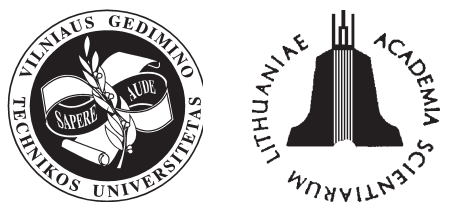

\title{
PERFORMANCE AND EXHAUST EMISSIONS OF DIRECT-INJECTION DIESEL ENGINE OPERATING ON RAPESEED OIL AND ITS BLENDS WITH DIESEL FUEL
}

\author{
Gvidonas Labeckas, Stasys Slavinskas \\ Dept of Transport and Power Machinery, Lithuanian University of Agriculture, \\ Student str. 15, P. O. Box LT-53067, Kaunas Academy, Lithuania \\ E-mail: gvidonas@info.lzuu.lt, sslavins@tech.lzuu.lt
}

Received 27 February 2005; accepted 25 June 2005

\begin{abstract}
The purpose of this research is to examine the effect of rapeseed oil (RO) inclusion into Diesel fuel (DF) on engine performance parameters.

During engine operation at 1400,1800 and $2200 \mathrm{~min}^{-1}$ the brake specific fuel consumption has on an average been increased by $0,104 \%, 0,134 \%$ and $0,156 \%$ for every $1 \%$ point increase in RO inclusion into DF. The maximum thermal efficiency values remain within $0,37-0,39$ intervals.

The maximum $\mathrm{NO}_{\mathrm{x}}$ emission increases with the mass percent of oxygen in the fuel blend and for RO and its blends RO75 and RO50 are higher by 9,2 \%, 20,7 \% and 5,1\%, respectively. Emissions of $\mathrm{NO}_{2}$ increase with an increasing content of RO premixed into DF.

When operating on pure RO and its blends RO75 and RO50 the maximum CO emission reduces by $40,5 \%-$ $52,9 \%$ and $7,2 \%-15,0 \%$, respectively. The smoke opacity generated from RO and its blends is also by $27,1 \%-$ $34,6 \%$ and $41,7 \%-51,0 \%$ lower.

Emissions of $\mathrm{HC}$ remain on a considerably low level ranging between 8 to $16 \mathrm{ppm}$ whereas during engine operation on pure RO they approach to about a zero level. Emissions of $\mathrm{CO}_{2}$ for $\mathrm{RO}$ and fuel blend $\mathrm{RO} 75$ are slightly higher.
\end{abstract}

Keywords: Diesel engine, rapeseed oil, fuel blends, performance efficiency, emissions, smoke opacity.

\section{Introduction}

The growing popularity of renewable fuels is based primarily upon urgent concern about environment pollution that increases rapidly because of the intense usage of fossil fuel resources that have naturally been accumulated in the earth over millions of years. Rapid increase of Diesel engined vehicles and powerful tractors has led to the ambient air pollution by $\mathrm{CO}_{2}, \mathrm{CO}, \mathrm{NO}_{\mathrm{x}}, \mathrm{HC}, \mathrm{PM}$ and other harmful species exhausted into atmosphere contributing to heat energy accumulation around the globe and creating so called "green-house" effect. This may be the answer as to why population suffers disasters caused by heavy rains and floods that occur because of the global climate changes. Vegetable oil based fuels applied as Diesel fuel (DF) extender could alleviate the environmental pollution contributing to closed cycle $\mathrm{CO}_{2}$ circulation.

Therefore, the main purpose of broad-scale usage of vegetable oil based fuels should be regarded, primarily, as a measure taken to solve ecological problems. Economical and other advantages should be considered as a second-rate business established to promote well-balanced development of the state strategy, create new jobs, extend the usage of non-food products and suspend for a while growing prices of mineral fuels. However, the practical usage of pure rapeseed oil (RO) for Diesel engine fuelling is aggravated because of its high density and viscosity, the fuel filter plugging and carbon deposits formation on the surface of inner parts of the combustion chamber.

Advantages and disadvantages related to the usage of RO for Diesel engine fuelling as well as the main properties of the tested oil have been discussed in previous investigations [1]. In addition, mixing of oil with lighter Diesel fuel improves the lubricating properties of fuel blends and compensates reduced sulphur content in Diesel which has been lowered in recent years from $2000 \mathrm{ppm}$ to $200-500 \mathrm{ppm}$ and even to $1 \mathrm{ppm}$ for some city buses [2]. The lubricity of rapeseed oil is known as superior comparing with conversional Diesel and his property is imparted to blends at levels above $20 \mathrm{vol} \%$ [3].

One of the methods that allows to reduce oil viscosity and improve its technical properties is RO mix- 
ing with conventional Diesel fuel [4-8]. However, due to the lower net heating value of RO mixing into Diesel fuel reduces the calorific value of the fuel blend resulting in engine power losses and higher brake specific fuel consumption (bsfc). Tests with a Ford 6610 tractor fitted with a $4.4 \mathrm{~L}$ unmodified, naturally aspirated Diesel engine indicate approximately $0,06 \%$ reduction in power output and $0,14 \%$ increase in bsfc for every $1 \%$ point increase of the semirefined rapeseed oil (SRO) inclusion into Diesel fuel [7].

Tests conducted in John Deere 4276T four cylinder, four stroke, direct-injection Diesel engine run on two different soybean oils, one of which had been deliberately oxidized and with their $20 \%$ blends with Diesel fuel proved that the smoke number, $\mathrm{CO}$ and HC decreased by $8 \%$ to $63 \%, 2 \%$ to $29 \%$, and $3 \%$ to $60 \%$, respectively, while $\mathrm{NO}_{\mathrm{x}}$ emissions increased by $0,5 \%$ to $18 \%$ [9]. The authors determined that $\mathrm{NO}_{\mathrm{x}}$ emissions are linearly correlated to the actual start of combustion and, hence, depend on the maximum gas pressure and temperature in the cylinder. Investigations with a four stroke, four cylinder, turbocharged, direct-injection John Deere 4045TF Diesel engine further indicate that for the same cetane number and the same start of combustion, $\mathrm{NO}_{\mathrm{x}}$ emissions are the same for Soybean Biodiesel and Diesel fuel [10].

It should be noted, however, that during prolonged operation on Diesel fuel and rapeseed oil blend the problems related to fuel filter clogging, deposits built-up on the inner parts of the combustion chamber, injector coking, injection pump and piston rings sticking and sump oil thickening can arise. Such problems have been experienced already in tests [7], therefore in the case of unmodified direct-injection Diesel engine the authors suggest SRO inclusion rates up to $25 \%$ mainly. However, 500-h test with a 3-cylinder, 4-stroke, air cooled, direct-injection Diter model 3253 Diesel engine fuelled with $10 \%$ waste vegetable oil and $90 \%$ Diesel fuel blend revealed no visual difference in carbon deposits and smoke between two fuels tested, the overall power loss reaching $12 \%$ occurred after $100 \mathrm{~h}$ of operation only [6].

In contrast to Diesel fuel crude oil does not proceed through thermal refining process therefore its composition differs as having some kind of complicated fractions that at high cylinder gas temperature are split into smaller hydrocarbons before fuel evaporation occurs. This could be considered as one of the main reasons as to why parts of carbon deposits accumulate on the injector nozzles and inner combustion chamber. Therefore, in spite of overall acceptable performance on neat oil and its blends with Diesel during long-term operation the engine reliability problems can arise. Experiments conducted on 2.2 L, di- rect-injection Kabota engine with machine vision system fitted and DIAS image grabber card installed on a Pentium computer disclosed that injector coking rate and combustion chamber deposits are significantly dependant upon used canola and soybean oil percent in Diesel fuel blends. Based on this study the authors came to the conclusion that only $2,5 \%$ oil blends would be the best candidate fuel for further durability testing [5]. Other oil fuel blends of $10 \%$ and higher would potentially result in durability problems.

Nitric oxide NO forms at the high temperature (above $2000 \mathrm{~K}$ ) burned gases behind the flame through chemical reactions of nitrogen and free oxygen. The higher gas temperature is, the higher the rate of NO emission can be expected. Although the formation and destruction of nitrogen oxides are not directly linked with the fuel combustion, however, the amounts of these species depend on cylinder gas temperature and environment created by combustion [11]. Experimentations on a Farymann type $18 \mathrm{D}$ air-cooled 4,2 kW one-cylinder Diesel engine further indicate that if gas temperature in the cylinder remains almost stable, mixing Diesel fuel and RME in different proportions does not lead to significant changes in $\mathrm{NO}_{\mathrm{x}}$ emissions depending on the blend [12].

The performance and emission characteristics of the engine run on vegetable oil and its blends with Diesel fuel depend on air-fuel mixture quality, actual start of combustion and heat release peculiarities, therefore testing results of different engines can vary substantially. Agricultural sector in Lithuania, Latvia, Estonia and other neighbouring countries differs itself as having up to $80 \%$ of tractors produced in Russia and Belarus mainly. Today a few Biodiesel tests have been conducted only with such engines [13,14], therefore the absence of reliable test results retards the overall usage of vegetable oil based fuels.

The purpose of this research was to investigate the influence of cold pressed rapeseed oil and its blends with Diesel fuel on a four cylinder, direct-injection Diesel engine performance and emission composition changes. The objectives of this study can be stated as follows:

1. To determine the effect of rapeseed oil mixing with Diesel fuel on blend viscosity and filtration properties as well as to conduct the comparative analysis of engine performance, the brake specific fuel consumption and fuel energy conversion efficiency when operating on baseline Diesel fuel, pure rapeseed oil and their blends over a wide range of loads and speeds.

2. To examine the emission composition changes including nitrogen oxides $\mathrm{NO}_{\mathrm{x}}$, carbon monoxide $\mathrm{CO}$, unburned hydrocarbons $\mathrm{HC}$ and smoke opacity of the exhausts when operating alternately on pure rapeseed oil, Diesel fuel and their blends over a wide range of loads and revolutions per minute. 


\section{Experimental apparatus and methodology of the research}

Tests were conducted on a completely commissioned four cylinder, four stroke, naturally aspirated, water-cooled, $59 \mathrm{~kW}$ direct-injection Diesel engine D-243 with splash volume $V_{1}=4,75 \mathrm{dm}^{3}$, bore of 110 $\mathrm{mm}$, stroke of $125 \mathrm{~mm}$, compression ratio $\varepsilon=16: 1$ and toroidal type combustion chamber. The fuel was delivered by an in line fuel injection pump through five holes injection units with the initial fuel delivery start at $25^{\circ}$ before top dead centre (BTDC). The needle valve lifting pressure for all injectors was set to $17,5 \pm 0,5 \mathrm{MPa}$.

The fuelling system was modified by means of installing two joined in parallel fine porous fuel filters. The fuel overrunning through the injection pump pressure control valve was forwarded to the transfer pump, whereas the fuel droplets penetrating through the injector needle valve were collected in the fuel metering vessel.

To obtain the baseline parameters the engine was operated on Diesel fuel grade C first. Load characteristics were taken at constant crankshaft revolutions of $1400,1600,1800,2000$ and $2200 \mathrm{~min}^{-1}$. After all load characteristics were taken from the engine performance on Diesel, three blends were prepared by splash mixing DF and RO in the following proportions by volume: $75 \%$ Diesel fuel and $25 \%$ rapeseed oil (RO25), $50 \%$ Diesel fuel and $50 \%$ rapeseed oil (RO50) and $25 \%$ Diesel fuel and $75 \%$ rapeseed oil (RO75) and similar experiments were conducted over the same range of engine loads and revolution frequencies. Afterwards, the Diesel engine was fuelled with pure $\mathrm{RO}$, its performance characteristics were taken again and exhaust gas emissions measured over the same test ranges.

The torque of the engine was measured with an electrical AC dynamometer and crankshaft evolutions were measured with a stand tachometer TSFU-1, the mass fuel consumption was determined by weighting it on electronic scales VLK-500 and volumetric air consumption - with gas counter RG-400-1-1.5.

The amounts of carbon monoxide $\mathrm{CO}(\mathrm{ppm})$, and dioxide $\mathrm{CO}_{2}$ vol \%), nitric oxide $\mathrm{NO}$ (ppm) and nitrogen dioxide $\mathrm{NO}_{2}$ (ppm) in the exhaust were measured with Testo 33 gas analyser. This apparatus was employed to determine the instant values of air-tofuel equivalence ratio $\lambda$. The amounts of unburned hydrocarbons $\mathrm{HC}$ (ppm vol) and residual oxygen $\mathrm{O}_{2}$ (vol \%) in the exhaust gases were determined with the gas analyser TECHNOTEST Infrared Multigas Tank model 488 OIML.

Smoke opacity $D(\%)$ of the exhaust gases was measured with Bosch device RTT 100/RTT 110 in I$100 \%$ scale with $\pm 0,1 \%$ accuracy.

\section{The test results and analysis}

The dependency of fuel blend viscosity and its relative filtration coefficient $(\mathrm{mm} / \mathrm{s})$ which was determined as the fuel flow rate in $\mathrm{mm}^{3} / \mathrm{s}$ through control $100 \mathrm{~mm}^{2}$ area of fine porous paper element at constant fuel pressure drop $\Delta \mathrm{p}=10 \mathrm{kPa}$, on percentage of Diesel fuel premixed into rapeseed oil at ambient temperature of $20{ }^{\circ} \mathrm{C}$ are presented in Fig 1 . As one can see in the graphs crude oil filtration through the fuel filter under given testing conditions is as low as $0,077 \mathrm{~mm} / \mathrm{s}$ compiling approximately $4,1 \%$ related to Diesel fuel. Therefore, it is difficult to achieve at room temperature the necessary oil flow in the fuelling system and maintain rated power especially in the case of a plunger transfer pump.

As it is obvious from the graph the viscosity of rapeseed oil reduces rapidly and its filtration properties improve with Diesel fuel inclusion into fuel blend. Mixing of RO with lighter Diesel fuel improves filtration through a fine porous paper element and flow capacity for blends RO25, RO50, RO75 increases 1,7, 5,4 and 11,8 times, respectively. As one can see in the picture necessary fuel flow capacity through a fine porous filter element can be obtained at premixing ratio of $75 \% \mathrm{DF} / 25 \% \mathrm{RO}$ and higher. Rapeseed oil and Diesel fuel mixing by the mentioned proportion could be considered as suitable to maintain the fuel flow necessary for normal operation of the engine.

The viscosity of pure rapeseed oil, blends RO75, RO50, RO25 and Diesel fuel as a function of heating temperature is presented in Fig 2. At room temperature $\left(20^{\circ} \mathrm{C}\right.$ the viscosity of crude oil is very high $(78,6$ $\mathrm{mm}^{2} / \mathrm{s}$ ), i.e. about 22 times exceeds the corresponding value $\left(3,6 \mathrm{~mm}^{2} / \mathrm{s}\right)$ of conventional Diesel fuel. Mixing of RO with lighter Diesel fuel permits to reduce its viscosity and obtain corresponding viscosity

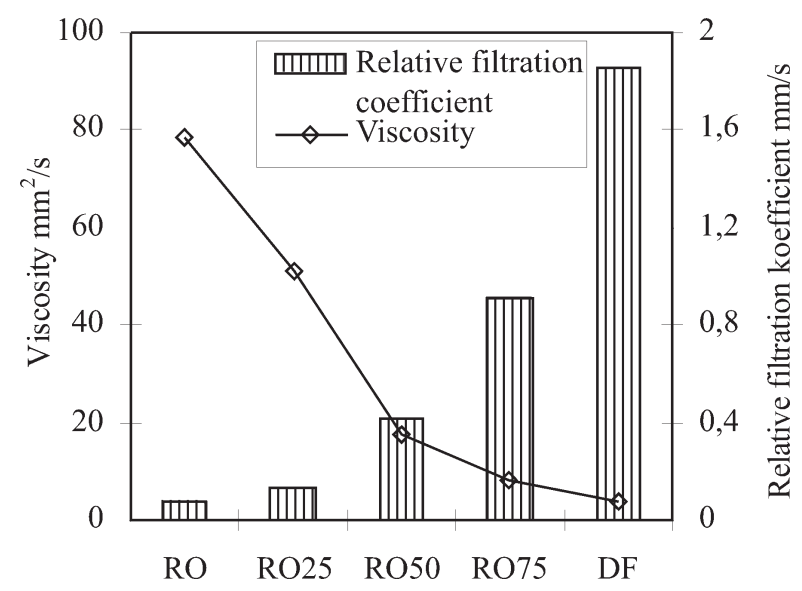

Fig 1. Dependency of viscosity and relative filtration coefficients of fuel blends on the percentage of Diesel premixed into rapeseed oil 


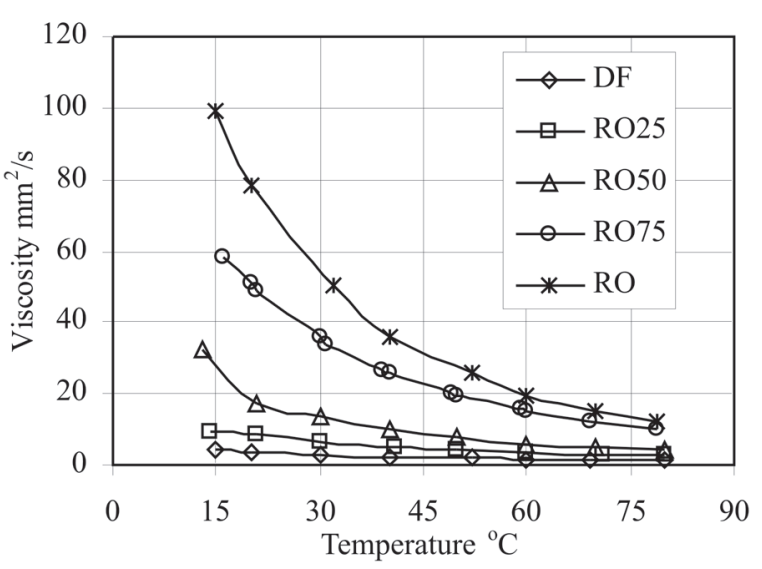

Fig 2. The effect of preheating temperature on the viscosity of various rapeseed oil and Diesel fuel blends

values of $51,2,17,4$ and $8,4 \mathrm{~mm}^{2} / \mathrm{s}$ for the tested blends.

To increase the filtration properties of vegetable oil and its blends with Diesel the fuel preheating method is widely used. Heating to the temperature of 50-60 ${ }^{\circ} \mathrm{C}$ can be regarded as an extra measure that reduces oil viscosity several times. The higher the percentage of oil included into Diesel fuel is, the higher is the effect of heating on blend viscosity. This method seems as being especially promising at low temperature range of $15^{\circ} \mathrm{C}$ to $40^{\circ} \mathrm{C}$. However, when operating on Diesel fuel blends with small amounts (up to $25 \%$ ) of RO included there one can obtain fuel viscosity more or less suitable for normal operation without extra heating.

Graphs of the brake specific fuel consumption as a function of load obtained during engine operation on pure RO, Diesel fuel and their blends at rotation speeds of 1400,1800 and $2200 \mathrm{~min}^{-1}$ have been superimposed as shown in Fig 3. All graphs proceed with the increasing load similar enough, however bsfc values increase about proportional with the amount of RO premixed into Diesel fuel. After the inclusion into Diesel fuel $25 \%, 50 \%, 75 \%$ of rapeseed oil and, finally, fuelling the engine with pure RO, the minimum bsfc values were increased on an average by 2,7\%, 6,8 \%, 9,9\% and 11,6\%, correspondingly. Given results remain in good agreement with studies made by Graboski M.S. and McCormick R. L. [3], where it was determined that the fuel economy based upon energy content is independent on the fuel mixture fed to the engine. This preposition suggests that neat rapeseed oil and its blends with Diesel exhibit bsfc in mass inversely proportional to their calorific value.

As it is obvious from graphs in Fig 3, that bsfc decreases with the load remaining at 1400,1800 and $2200 \mathrm{~min}^{-1}$ revolutions at slightly higher levels for the fuel blends with higher oil content premixed into Die-
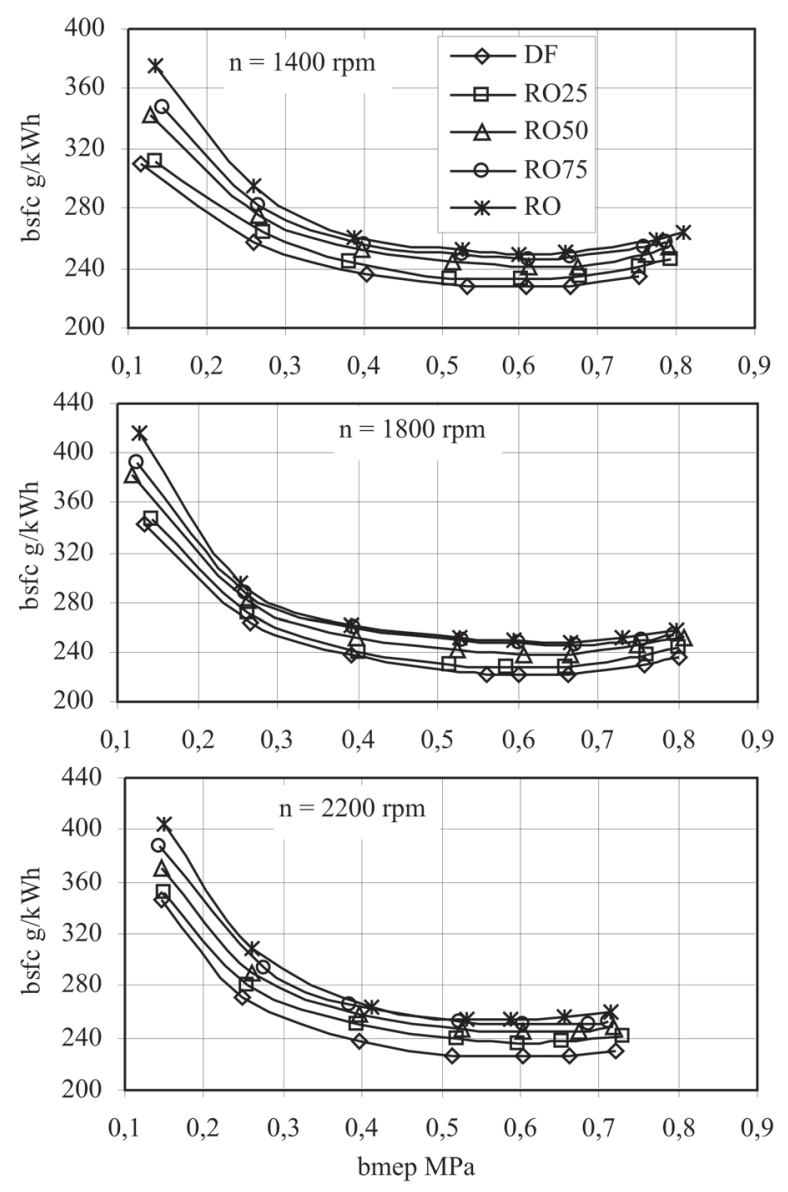

Fig 3. Brake specific fuel consumption (bsfc) as a function of engine load (bmep) at various speeds (n)

sel. Test does not reveal the significant reduction in power output, however, the minimum bsfc values have on an average been increased by $0,104 \%, 0,134 \%$ and $0,156 \%$, respectively for every $1 \%$ point increase in RO inclusion into Diesel fuel. However, when operating under easy loads bsfc behaviour with the oil content in fuel blend is a bit different. At bmep H" 0,15 MPa bsfc values increase more intensively with RO content in Diesel fuel, but, in contrast to heavy loading conditions, the sensitivity to oil inclusion diminishes with the speed indicating 0,222 \%, 0,200\% and $0,135 \%$, respectively. The increase of bsfc in grams per unit energy developed depends actually on both engine load and its rotation speed and this conclusion should be taken into account when discussing about $\mathrm{RO}$ inclusion rate that could be considered as suitable for particular engine performance conditions.

For further analysis brake thermal efficiency curves as a function of load for Diesel engine run on the conventional fuel, pure RO and their blends have been superimposed as shown in Fig 4. At the speed of $1400 \mathrm{~min}^{-1}$ the highest brake thermal efficiency value 0,39 was obtained for pure RO and slightly 


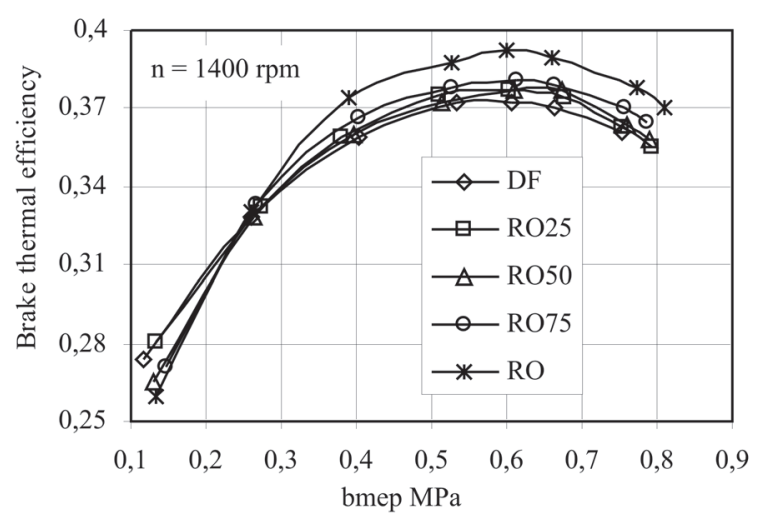

Fig 4. Brake thermal efficiency as a function of engine load (bmep) when operating on pure rapeseed oil, Diesel fuel and their blends

lower 0,37 for Diesel fuel. The maximum thermal efficiency values for RO-Diesel blends remain within the appointed interval showing a slight increase in performance efficiency due to the oil inclusion into Diesel fuel. Test results of a Petter model ACI single cylinder, energy-cell Diesel engine also proved a bit higher brake thermal efficiency at moderate loads for neat RO and its $25 \mathrm{vol} \%$ blends with Diesel [8].

Within the revolution range from 1600 to 2200 $\mathrm{min}^{-1}$ brake thermal efficiency values increase gradually with the load, but it is difficult to determine any reliable dependency on the fuel composition. At the minimum load different blends exhibit the same brake thermal efficiency of approximately 0,25 , therefore it was decided not to scrutinise the dependencies in detail. Test results show that under normal operating conditions the fuel energy conversion efficiency remains independent on the content of RO premixed into Diesel fuel.

As it follows from the literature analysis $[3,15]$ the total $\mathrm{NO}_{\mathrm{x}}$ concentration in the exhausts determined as a sum of both pollutants $\mathrm{NO}$ and $\mathrm{NO}_{2}$ depends on the fuel feedstock, indigenous oxygen content in fuel composition, its volatility, iodine number and cetane number, actual start of combustion and other variables. usage of rapeseed oil as low volatile fuel may decrease premixed burning portion of combustion, reduce peak cylinder gas temperature and formation of $\mathrm{NO}_{\mathrm{x}}$ but, on the other hand, its oxygenated nature and longer auto-ignition delay are not ready for such contribution [16].

As one can see in graphs of Fig 5, $\mathrm{NO}_{\mathrm{x}}$ emissions at wide range of revolutions increase gradually with the load, reaching at its high loads, the maximum values which depend on the fuel composition and engine speed. Maximum $\mathrm{NO}_{\mathrm{x}}$ emissions for Diesel fuel indicate slight decrease with the speed reaching correspondingly 1 911, 1674 and $1386 \mathrm{ppm}$, whereas $\mathrm{NO}_{\mathrm{x}}$ emissions for crude $\mathrm{RO}$ and its blends show con-
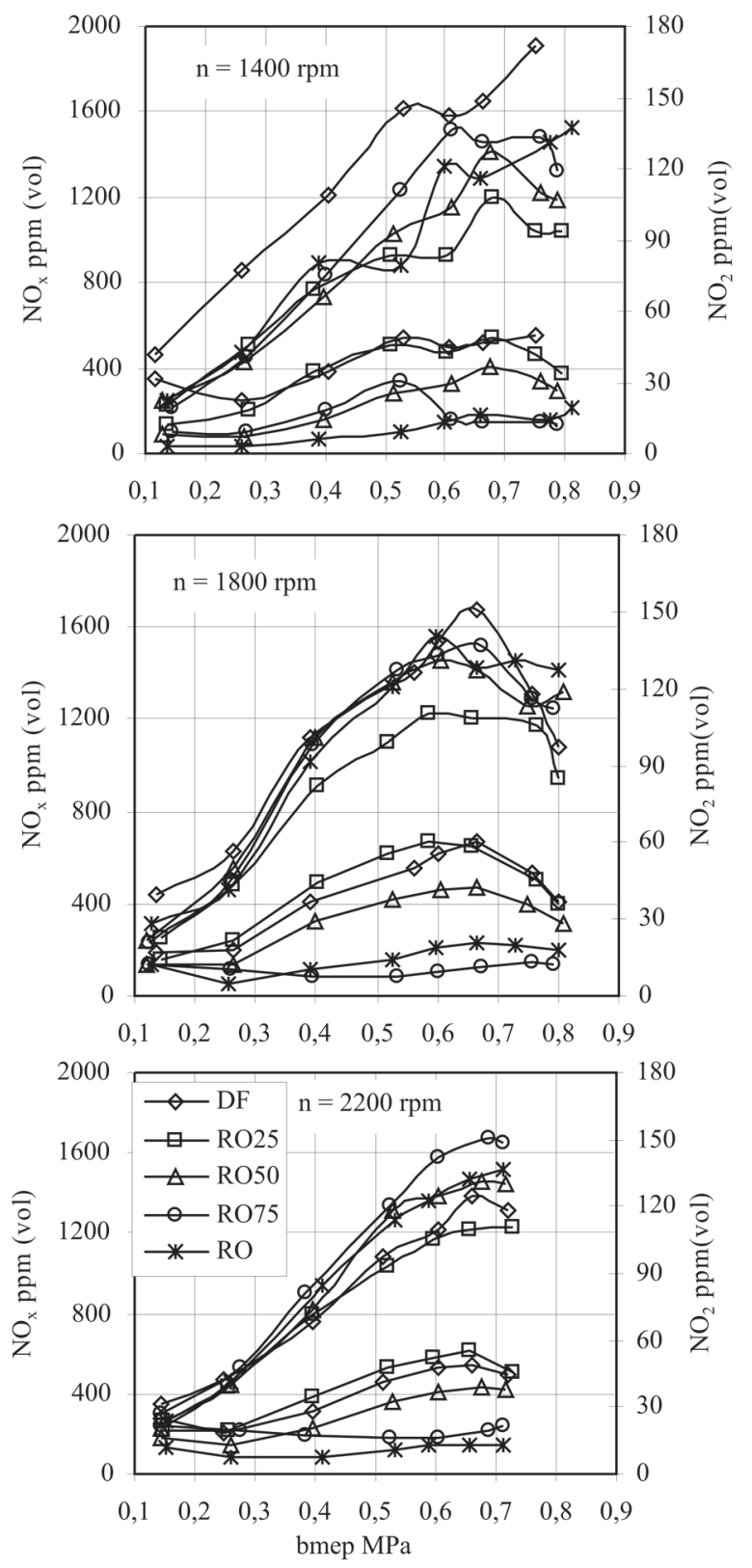

Fig 5. Total nitrogen oxides $\mathrm{NO}_{x}$ and dioxide $\mathrm{NO}_{2}$ emissions as a function of engine load (bmep) at various rotation speeds (n)

trary tendencies tending rather to increase with the speed. Mentioned $\mathrm{NO}_{\mathrm{x}}$ emission behaviour can be related to fuel composition which in the case of oxygenated fuel maintains at equivalent loads a bit higher air-to-fuel equivalence ratio.

When running a fully loaded engine at the minimum $1400 \mathrm{~min}^{-1}$ speed pure RO and its blends RO75, RO50, RO25 produce by $20,0 \%$ and $21,0 \%, 26,2 \%$, $37,4 \%$ lower $\mathrm{NO}_{\mathrm{x}}$ emission compared with conventional Diesel. Lower $\mathrm{NO}_{\mathrm{x}}$ emission can be achieved, presumably, because of lower quantity of fuel premixed for rapid reactions at the first stages of combustion process. $\mathrm{NO}_{\mathrm{x}}$ emissions increase, however, 
with the oil inclusion into Diesel fuel reaching for tested blends the maximum values of 1 196, 1411 and 1510 ppm, respectively. Crude oil exhibits maximum $\mathrm{NO}_{\mathrm{x}}$ emission of $1528 \mathrm{ppm}$ that is a slightly higher related to that of RO75 fuel blend.

At higher $1800 \mathrm{~min}^{-1}$ revolutions $\mathrm{NO}_{\mathrm{x}}$ emission for pure RO, RO75 and RO50 blends appears at approximately the same level as that for Diesel fuel. Only blend $\mathrm{RO} 25$ suggests $\mathrm{NO}_{\mathrm{x}}$ emission on an average by $26,7 \%$ lower. Maximum $\mathrm{NO}_{\mathrm{x}}$ emission generated from $\mathrm{RO}$ is also by 7,0 \% lower than that of Diesel fuel. However, as engine speed increases up to the rated $2200 \mathrm{~min}^{-1}$ value, maximum $\mathrm{NO}_{\mathrm{x}}$ emission for pure RO, RO75 and RO50 blends becomes higher by 9,2\% (128 ppm), 20,7\% (287 ppm) and 5,1\% (71 $\mathrm{ppm}$ ) related to Diesel fuel (1 $386 \mathrm{ppm}$ ). Again, fuel blend RO25 does effectively reduce pollutants suggesting $\mathrm{NO}_{\mathrm{x}}$ emission about $11,7 \%$ lower. As it is obvious, the flame temperature changes alone cannot adequately explain the observed variations in $\mathrm{NO}_{\mathrm{x}}$ emission for oxygenated fuel blends [9].

Tests with 6V92TA MUI engine rebuilt to 1987 EPA D-bus disclosed that for both rapeseed (canola) and soy ester blends with CARB and U.S. low sulphur Diesel fuels $\mathrm{NO}_{\mathrm{x}}$ increases in proportion to the weight percent of oxygen in the fuel composition. For $20 \%$ soy methyl ester in CARB Diesel due to the effect of oxygenates unburned $\mathrm{HC}, \mathrm{CO}$ and $\mathrm{PM}$ were decreased by $16,7,20,2$ and $6,1 \%$, while $\mathrm{NO}_{\mathrm{x}}$ simultaneously increased by $4,5 \%$ [3]. It seems pretty clear that the same tendencies remain in value in the case of D-243 Diesel engine because maximum $\mathrm{NO}_{\mathrm{x}}$ emissions for tested oil blends with the mass oxygen contents of $3,0 \%, 5,6 \%$ and $8,2 \%$ increase to 1224 , 1457 and $1673 \mathrm{ppm}$, respectively. Only for pure RO that distinguishes itself as having the biggest 10,8\% oxygen content, maximum $\mathrm{NO}_{\mathrm{x}}$ emission of $1514 \mathrm{ppm}$ is lower related to that of blend RO75. Observed peculiarities have not been studied completely serving as a reason for a bit different results reported in the literature especially in the terms of Biodiesel effect on $\mathrm{NO}_{\mathrm{x}}, \mathrm{CO}, \mathrm{HC}, \mathrm{PM}$ and other pollutants exhausted.

Nitrogen dioxide emissions increase slightly with the load reaching maximum $\mathrm{NO}_{2}$ values at between 12 to $63 \mathrm{ppm}$ and remaining about ten times as much lower in comparison to that of nitric monoxide. Maximum $\mathrm{NO}_{2}$ emissions of 49-63 ppm were measured for Diesel fuel and blend RO25. In contrast to NO, emissions of $\mathrm{NO}_{2}$ have tendency to reduce with the amount of oil premixed into Diesel fuel. Experiments with a single cylinder direct-injection Diesel engine show that $\mathrm{NO}_{2}$ emissions for vegetable oils may actually be lower than that of Diesel fuel [4]. According our test results maximum $\mathrm{NO}_{2}$ emissions for pure oil and blend RO75 amount from 12 to 22 ppm only.
Lower $\mathrm{NO}_{2}$ emissions have been obtained, probably, because of oxygenated nature of RO that improves fuel combustion and boosts cylinder gas temperature speeding up conversion back to NO [11].

Carbon monoxide $\mathrm{CO}$ emissions as a function of load (bmep) at revolutions of 1 400, 1800 and 2200 $\min ^{-1}$ are given in Fig 6. The first issue is clear visible when operating on pure oil the fully loaded engine exhausts correspondingly by $40,5 \%, 46,0 \%$ and $52,91 \%$ less CO than conventional Diesel. At low 1 $400 \mathrm{~min}^{-1}$ speed emissions of CO through all load range remain as low as about $350 \mathrm{ppm}$ with a rapid increase at heavy loads only. As one can see, the oxygenated blends demonstrate $\mathrm{CO}$ emissions behaviour with the load very similar to that of Diesel fuel. When operating under maximum load air-to-fuel equivalence ratio is diminished beyond 1,5 values therefore the local oxygen deficiency may occur to burn fuelrich mixture completely.

As engine speed and cylinder gas turbulence intensity increase, conditions for burning of big oil portions improve and $\mathrm{CO}$ emissions at heavy loads become lower. Environmentally more friendly $\mathrm{CO}$ emissions ranging with the load at between 400-800 ppm sustain equally well at maximum torque revolutions $1800 \mathrm{~min}^{-1}$ and rated $2200 \mathrm{~min}^{-1}$ speed. At the mentioned speeds maximum $\mathrm{CO}$ emissions for blends RO75 and RO50 are lower by 7,2\%-11,9\% and $13,5 \%-15,0 \%$, respectively. Only for blend RO25 CO emission curves reflect a bit higher values tending to converge to the ones obtained during engine operation on Diesel fuel. When running the engine at a fully opened throttle $\mathrm{CO}$ emissions reach the top values of 1100-1300 ppm.

However, at very easy loads emissions of $\mathrm{CO}$ show the tendency to be slightly higher again. In spite of overall fuel-lean mixture corresponding to air-fuel equivalence ratio $\lambda \approx 5,0-6,0$, poor atomisation and slow evaporation at low cylinder gas temperature can lead to incomplete combustion of small oil portions injected per cycle.

According to Ref. [11] soot is produced by a pyrolysis reaction in the flame front at high gas temperature of about 1000 to $2000 \mathrm{~K}$. It appears even in sufficient amounts of air to burn all the fuel injected because the mixture combustion proceeds through the dissociation of hydrocarbons. Inter-media combustion products such as acetylene $\mathrm{C}_{2} \mathrm{H}_{2}$ and polycyclic aromatic hydrocarbons are known as the causers of soot formation. The eventual emission of soot depends on the balance of soot particles formation and their oxidation speeds. Smoke transparency is affected actually by both the soot particles and the amounts of variable size volatile or soluble unburned organic compounds (PM) suspended in the exhausts [17]. 

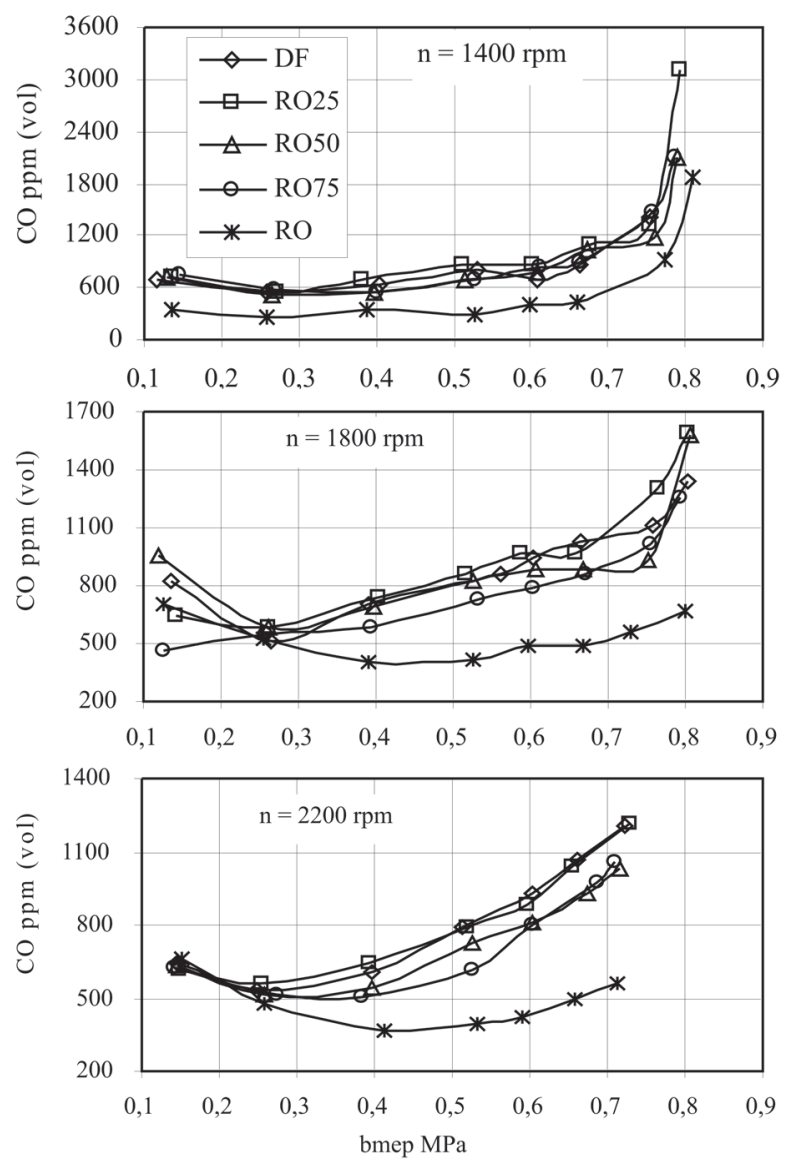

Fig 6. Carbon monoxide emissions as a function of load (bmep) at various speeds (n)

At speeds 1 400, 1800 and $2200 \mathrm{~min}^{-1}$ and fully opened throttle the engine develops the control torque corresponding to loads of bmep $=0,77,0,76$ and 0,68 $\mathrm{MPa}$. Under given testing conditions the biggest smoke opacity of $96 \%, 47 \%$ and $26 \%$ was generated from Diesel fuel whereas pure RO exhibited by 27,1 \%, 34,0 \% and 34,6 \% lower smoke (Fig 7). Visibly lighter smoke along with drastically diminished $\mathrm{CO}$ and $\mathrm{HC}$ emissions accompanied by slightly higher $\mathrm{NO}_{\mathrm{x}}$ concentration was obtained because of higher oxygen content in $\mathrm{RO}$ composition. The mentioned above emission changes remain in good agreement with a higher combustion efficiency obtained for pure rapeseed oil.

At reduced $1400 \mathrm{~min}^{-1}$ speed maximum smoke opacity for blends RO25, RO50 and RO75 is lower by $41,7 \%, 49,0 \%$ and $51,0 \%$, respectively. At higher 1800 and $2200 \mathrm{~min}^{-1}$ speeds the gas smoke emerging from blends RO50 and RO75 is quite similar to that generated by pure $\mathrm{RO}$ whereas maximum smoke values of $44 \%$ and $22 \%$ generated by RO25 blend locate themselves in close proximity to that of Diesel fuel. In this particular case slightly higher smoke accompanied by higher $\mathrm{CO}$ and $\mathrm{HC}$ emissions correlates reasonably well with reduced $\mathrm{NO}_{\mathrm{x}}$ concentration.
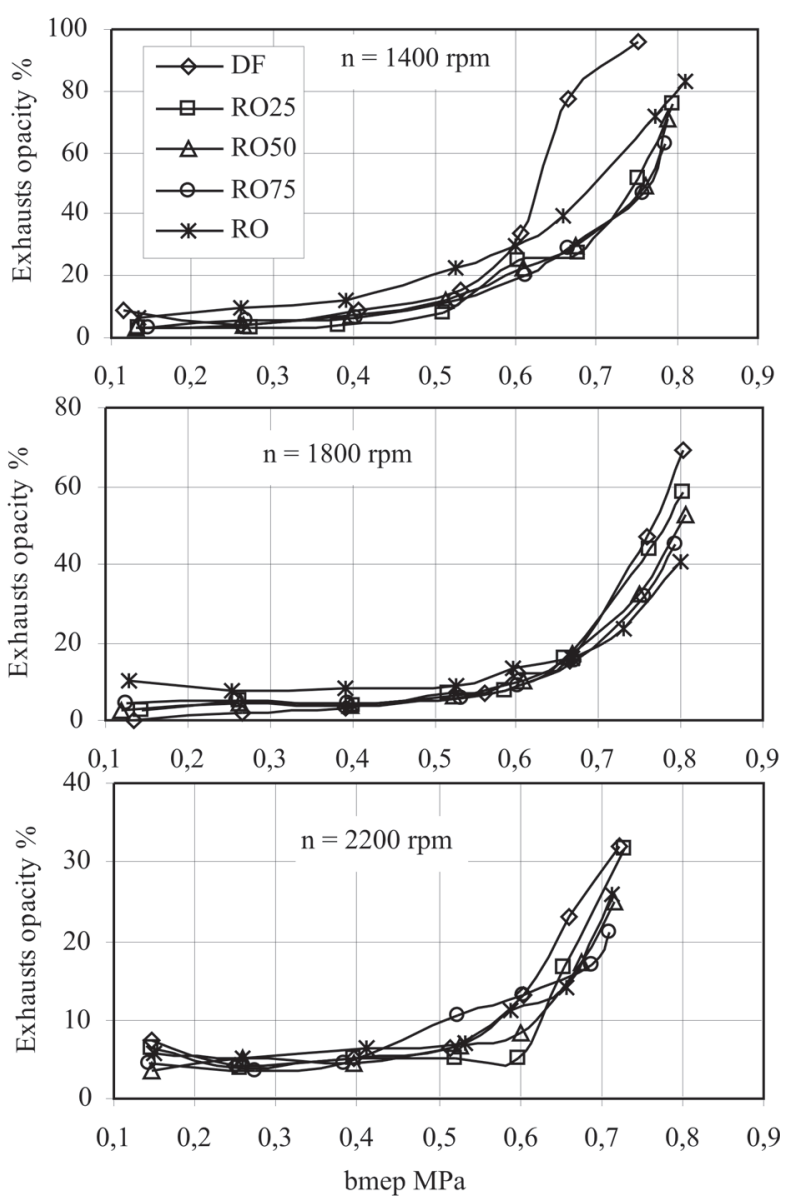

Fig 7. Opacity of Diesel exhausts as a function of load (bmep) at various speeds (n)

The amount of residual oxygen in the exhausts was for blend RO25 as high as 10,2-12,6 \% comparing with 9,62-12,4\% for Diesel fuel.

The emissions of unburned hydrocarbons depend on engine design, mixture composition and variation in cylinder-to-cylinder of air-to-fuel equivalence ratio. As it follows from Fig 8, HC emissions were negligible and changed between 8 to 16 ppm mainly. In the graphs one can monitor a slight $\mathrm{HC}$ emission increase with the load and quantity of fuel injected however it is difficult to determine any reliable dependency on the blend. HC emissions for pure RO at the tested speeds and loads remain on a very low level approaching to measurements accuracy available.

Low HC emissions have been measured, probably, due to the condensation of the heaviest hydrocarbons in the sampling line upstream of the detector [17]. The majority of the fatty acids have complicated 16 and 18 carbon length chains that are liable to condense [3]. The maximum temperature of the exhausts for all fuels tested was similar enough ranging between $525-535^{\circ} \mathrm{C}$. Higher oil viscosity and its sticking properties may contribute in sealing combustion chamber cavities liable to quench flame [11]. 


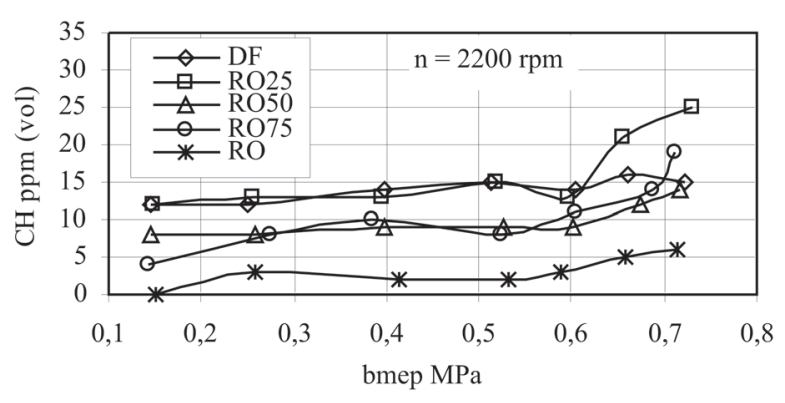

Fig 8. Hydrocarbons HC emissions as a function of load (bmep) at various speeds (n)

As it is obvious from the graphs presented in Fig 9, the emissions of carbon dioxide increase smoothly with the load exhibiting slightly higher $\mathrm{CO}_{2}$ amounts produced by rapeseed oil and blend $\mathrm{RO} 75$. However, due to the total sun energy a major part of $\mathrm{CO}_{2}$ emission exhausted during the combustion of biofuels will be returned back by growing oil plants to produce new hydrocarbons and release free oxygen

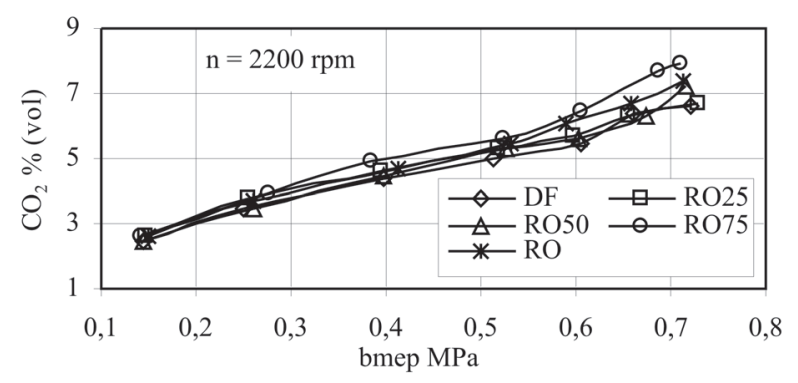

Fig 9. Dependencies of carbon dioxide emissions on engine load (bmep)

into atmosphere.

\section{Conclusions}

1. The increase of the brake specific fuel consumption due to rapeseed oil mixing into Diesel fuel depends on both engine load and its rotation speed. Minimum bsfc values at speeds of 1400,1800 and $2200 \mathrm{~min}^{-1}$ have on average been increased by $0,104 \%, 0,134 \%$ and $0,156 \%$ for every $1 \%$ point increase in RO inclusion into Diesel fuel. At easy loads the engine is more sensitive to oil inclusion into Diesel fuel therefore bsfc values are increased by $0,222 \%$, $0,200 \%$ and $0,135 \%$, respectively.

2. The fuel energy conversion efficiency does not depend very much on the percentage of rapeseed oil included into Diesel fuel and the maximum thermal efficiency values for Diesel fuel, pure RO and their blends throughout a wide range of the engine the speed remains within 0,37-0,39 interval.

3. At low revolutions $\mathrm{NO}_{\mathrm{x}}$ emissions for pure oil and its blends with Diesel proceed at lower levels, however, they increase with the mass percent of oxygen in the fuel blend. At the rated $2200 \mathrm{~min}^{-1}$ speed maximum $\mathrm{NO}_{\mathrm{x}}$ emissions for pure RO, blends RO75 and RO50 are higher by 9,2\%, 20,7 \% and 5,1\% than that of Diesel fuel. The only fuel blend RO25 suggests throughout all speed range maximum $\mathrm{NO}_{\mathrm{x}}$ emission by 37,4-11,7\% lower related to conventional Diesel. Emissions of $\mathrm{NO}_{2}$ indicate clear reduction tendencies with increasing content of RO premixed into Diesel fuel.

4. The substitution of Diesel fuel by RO reduces maximum $\mathrm{CO}$ emission by $40,5 \%, 46,0 \%$ and $52,9 \%$, respectively. $\mathrm{CO}$ emissions for blends $\mathrm{RO} 75$ and RO50 at the maximum torque and rated power are lower by approximately 7,2 \%-15,0 \% whereas blend $\mathrm{RO} 25$ exhibit $\mathrm{CO}$ emission nearly the same as conversional Diesel.

5. The maximum smoke opacity for pure RO is lower by $27,1 \%-34,6 \%$ however under easy operating conditions the emergence of white coloured vapours may reduce slightly the transparency of the exhausts. Visible smoke arising from oxygenated fuel blends is lower by $41,7 \%-51,0 \%$ related to Diesel fuel.

6. The emissions of unburned hydrocarbons for fuel blends remain at a considerably low level ranging with the loads and revolutions at between 8 to 16 ppm mainly whereas $\mathrm{HC}$ emissions for pure RO appear at about zero level. Emissions of $\mathrm{CO}_{2}$ are slightly higher for pure RO and blend RO75 that correlate reasonably well with higher fuel consumption in mass.

Test results indicate that rapeseed oil inclusion into Diesel fuel up to 25 vol \% could be considered as a possible fossil fuel extender. The application of rapeseed oil and its blends with Diesel for engine fuelling should be dependent, however, on long-term endurance test results.

\section{References}

1. Labeckas, G.; Slavinskas, S. Performance of direct-injection off-road Diesel engine on rapeseed oil. Renewable Energy (article in press).

2. Krahl, J.; Munack, A.; Schröder, O.; Stein, H.; Dutz, M. Exhaust Gas Emissions and Health Effects from Biodiesel, Fossil Diesel Fuel, and Swedish Low Sulphur Diesel Fuel MKI. Paper Number: 02-6082. An ASAE Annual International Meeting Presentation, Chicago, Illinois, USA, 28-31 July 2002, p. 13.

3. Graboski, M. S.; McCormick, R. L. Combustion of Fat and Vegetable Oil Derived Fuels in Diesel Engines. Progress in Energy and Combustion. Scientific, Vol 24, 1998, p. 125-164, Elsevier Science Ltd.

4. Altin, R.; Çetinkaya, S.; Yücesu, H. S. The potential of using vegetable oil fuels as fuel for Diesel engines. Energy Conversion and Management, 2001, Vol 42, p. 529-538. 
5. Jones, S. T.; Peterson, C. L.; Thompson, J. C. Used Vegetable Oil Fuel Blend Comparisons Using Injector Coking in a DI Diesel Engine. Paper Number: 01-6051. An ASAE Annual International Meeting Presentation, Sacramento, California, USA, 30 July-01 August, 2001, p. 26.

6 Dorado, M. P.; Arnal, J. M.; Gomez, J.; Gil, A.; Lopez, F. J. The Effect of a Waste Vegetable Oil Blend with Diesel Fuel on Engine Performance. Transactions of the ASAE, Vol 45(3), 2002, p. 519-523.

7. McDonnell, K. P.; Ward, S. M.; McNulty, P. B.; HowardHildige, R. Results of Engine and Vehicle Testing of Semirefined Rapeseed Oil. Transactions of the ASAE, Vol 43(6), 2000, p. 1309-1316.

8. Nwafor, O. M. I.; Rice, G. Performance of Rapeseed Oil Blends in a Diesel Engine. Applied Energy, Vol 54(4), 1996, p. 345-354.

9. Monyem, A.; Gerpen, J. H. V.; Canakci, M. The Effect of Timing and Oxidation on Emissions from Biodiesel Fuelled Engines. Transactions of the ASAE, Vol 44(1), 2001, p. 35-42.

10. Tat, M. E.; Gerpen, J. H. V. Fuel Property Effects on Biodiesel. Paper Number: 036034. An ASAE Annual International Meeting Presentation, Las Vegas, Nevada, USA, 27-30 July 2003, p. 16.

11. Heywood, J. B. Internal Combustion Engine Fundamentals. Co - Singapore for manufacture and export (International edition), 1988. $930 \mathrm{p}$.

12. Krahl, J.; Baum, K.; Hackbarth, U.; Jeberien, H.-E.; Munack, A.; Schütt, C.; Schröder, O.; Walter, N.;
Bünger, J.; Müller, M. M.; Weigel, A. Gaseous Compounds, Ozone Precursors, Particle Number and Particle Size Distributions, and Mutagenic Effects Due to Biodiesel. Transactions of the ASAE, Vol 44(2), 2001, p. 179-191.

13. Labeckas, G.; Slavinskas, S. The research of biofuels usage in Diesel engine. In: Proceedings of International conference TRANSBALTICA-99/ Vilnius Gediminas Technical University and Lithuanian Academy of Science. Vilnius: Technika, 1999, p. 409-415 (in Lithuanian, abstracts in English).

14. Labeckas, G.; Slavinskas, S.; Ignatavičius, T. The Research of Direct Injection Diesel Engine Performance Parameters during Operation on Pure Rapeseed Oil. Research papers of Lithuanian University of Agriculture VAGOS, Vol 57(10), 2003, p. 117-123.

15. Peterson, C. L.; Taberski, J. S.; Thompson, J. C.; Chase, C. L. The Effect of Biodiesel Feedstock on Regulated Emissions in Chassis Dynamometer Tests of a Pickup Truck. Transactions of the ASAE, Vol 43(6), 2000, p. 1371-1381.

16. Nwafor, O. M. I.; Rice, G.; Ogbonna, A. I. Effect of advanced injection timing on the performance of rapeseed oil in diesel engines. Renewable Energy, Vol 21, 2000, p. 433-444.

17. Gratton, M. R.; Hansen, A. C. Diesel Engine Emissions Characteristics and Measurement Requirements of Biofuels. Paper Number: 036032. An ASAE Annual International Meeting Presentation, Las Vegas, Nevada, USA, 27-30 July 2003, p. 11. 